\title{
Immunomagnetic Diffractometry for Detection of Diagnostic Serum Markers
}

Ghanashyam Acharya, Chun-Li Chang, Derek D. Doorneweerd, Erina Vlashi, Walter A. Henne, Lynn C Hartmann, Philip S. Low,

Cagri A. Savran

\section{Supplementary information}

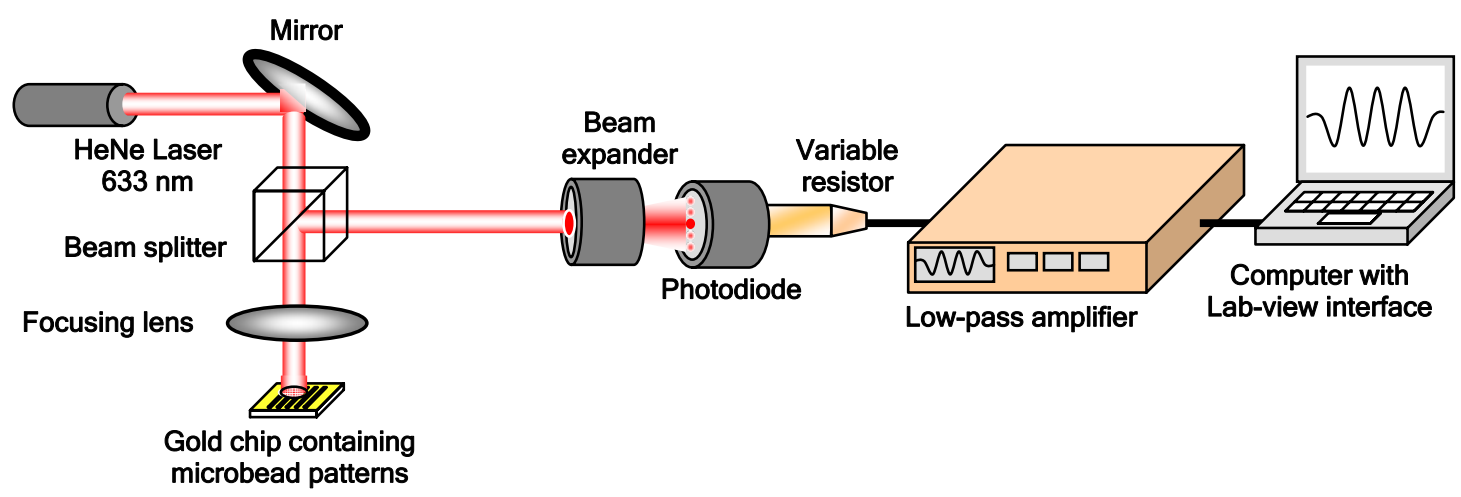

Supplementary Figure S1. Schematic of the optical diffraction measurement system.

\section{Micro-BCA (Bicinchoninic Acid) Protein Assay}

Micro-BCA assay experiments were performed to calculate the number of FR molecules captured by single Ab-bead (for the solution with $11 \mathrm{nM} \mathrm{FR}$ ). Concentration of FR before and after incubation with Ab-beads was determined by using a Micro-BCA protein assay reagent kit (Pierce Biotechnology). A set of protein standards from bovine serum albumin (BSA) were freshly prepared with concentrations ranging from 0 to $200 \mu \mathrm{g} / \mathrm{ml}$ using phosphate buffered saline (PBS) as diluent. The Working Reagent (WR) was prepared according to the instructions provided with the Micro-BCA Kit. $1.0 \mathrm{ml}$ of each standard and the FR solutions were pipetted into test tubes, and $1 \mathrm{ml}$ of WR was added to each tube and mixed well. The tubes were covered and incubated at $60{ }^{\circ} \mathrm{C}$ for $1 \mathrm{~h}$ followed by cooling to room temperature. The absorbance of all the BSA standards and FR solutions was measured within 10 minutes at $562 \mathrm{~nm}$ using a spectrophotometer (DU 640 Spectrophotometer, Beckman Coulter, Inc., CA). Neat PBS was used as a blank run. 
A standard curve was prepared by plotting the average of the $562 \mathrm{~nm}$ readings for each BSA standard $v s$ its concentration in $\mu \mathrm{g} / \mathrm{ml}$. This standard curve was used to determine the concentration of each unknown FR solution.

\section{Magnetic bead size distribution}

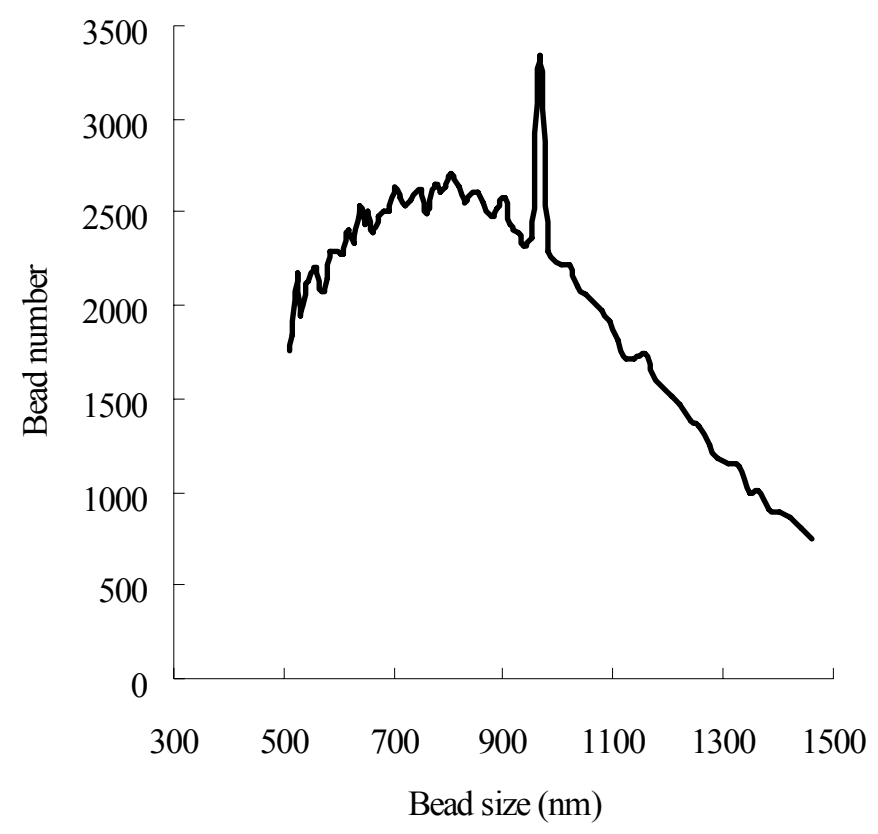

Supplementary Figure S2. Plot depicting the size distribution of the activated magnetic beads (obtained from Chemagen). 